\title{
The altered activity of P53 signaling pathway by STK11 gene mutations and its cancer phenotype in Peutz-Jeghers syndrome
}

Yu-Liang Jiang ${ }^{1,2+}$, Zi-Ye Zhao ${ }^{3,4+}$, Bai-Rong Li ${ }^{2+}, \mathrm{Fu} \mathrm{Yang}^{3}$, Jing Li ${ }^{2}$, Xiao-Wei Jin ${ }^{2}$, Hao Wang ${ }^{4}$, En-Da Yu ${ }^{4}$, Shu-Han Sun ${ }^{3^{*}}$ and Shou-Bin Ning ${ }^{2^{*}}$ (D)

\begin{abstract}
Background: Peutz-Jeghers syndrome (PJS) is caused by mutations in serine/threonine kinase 11 (STK11) gene. The increased cancer risk has been connected to P53 pathway.

Methods: PJS probands with STK11 mutation were included in the function analysis. P53 activity elevated by STK11 mutants was investigated using dual-luciferase reporter assay in vitro after constructing expression vectors of STK11 wild type and mutants generated by site-directed substitution. The association between the P53 activity and clinicopathological factors was analysis, especially the cancer history.

Results: Thirteen probands with STK11 mutations were involved, and within the mutations, C.G924A was novel. P53 activity elevation caused by 6 truncating mutations were significantly lower than that of STK11 wild type $(P<0.05)$. Family history of cancer was observed in 5 families. Within them, P53 activity was reduced and cancer occurred before 40 in 2 families, while it was not significantly changed and cancers happened after 45 in the other 3 families.

Conclusions: The affected P53 activity caused by STK11 mutations in PJS patients is significantly associated with protein truncation, while cancer risk in PJS can be elevated through pathways rather than P53 pathway. P53 activity test is probably a useful supporting method to predict cancer risk in PJS, which could be helpful in clinical practice.
\end{abstract}

Keywords: Peutz-Jeghers syndrome (PJS), STK11 gene, P53 gene, Cancer risk, Reporter gene technique

\section{Backgroud}

Peutz-Jeghers syndrome (PJS; OMIM \#175200) is an autosomal dominant disorder characterised by mucocutaneous melanin pigmentation (MP), gastrointestinal(GI) hamartomatous polyposis, and an increased risk for the development of various neoplasms [1, 2], which is rare with a low incidence of $1 / 50,000$ [3]. The cumulative lifetime risk is $20,43,71$, and $89 \%$ at ages of $40,50,60$ and 65 years, respectively [4].

\footnotetext{
* Correspondence: shsun@vip.sina.com; ningshoubin@126.com

${ }^{\dagger}$ Yu-Liang Jiang, Zi-Ye Zhao and Bai-Rong Li contributed equally to this work. ${ }^{3}$ Department of Medical Genetics, Naval Medical University, Shanghai 200433, China

${ }^{2}$ Department of Gastroenterology, Airforce General Hospital of PLA, Beijing 100142, China

Full list of author information is available at the end of the article
}

Germline mutations in the serine-threonine kinase 11 (STK11) gene on chromosome 19p13.3 were identified as a major genetic cause of PJS in 1998 [5, 6]. This gene is divided into 9 coding exons that encode a 433 amino-acid protein, which acts as a tumor suppressor. The STK11 protein is mainly comprised of 3 major domains: an $\mathrm{N}$-terminal regulatory domain, a catalytic kinase domain, and a $\mathrm{C}$ terminal regulatory domain [7]. Amino acids 49-309 of STK11 are the catalytic kinase domain, which can form a complex with STRAD and scaffold protein 25 (MO25) to maintain kinase activation [8]. Several studies have described a role of STK11 in cell cycle arrest [9], P53 mediated apoptosis [10], Wnt signaling $[11,12]$, TGF- $\beta$ signaling [13], Ras induced cell transformation [14], and cell polarity [15-18].

(c) The Author(s). 2018 Open Access This article is distributed under the terms of the Creative Commons Attribution 4.0 International License (http://creativecommons.org/licenses/by/4.0/), which permits unrestricted use, distribution, and reproduction in any medium, provided you give appropriate credit to the original author(s) and the source, provide a link to the Creative Commons license, and indicate if changes were made. The Creative Commons Public Domain Dedication waiver (http://creativecommons.org/publicdomain/zero/1.0/) applies to the data made available in this article, unless otherwise stated. 
P53, the most widely studied tumor suppressor gene, regulates of the expression of various genes that are related to cell cycle arrest, DNA damage repair and apoptosis [19], and furtherly controls the cell proliferation and apoptosis. P53 gene mutations have been found in about $50 \%$ of human cancers, suggesting the important role of P53 inactivation in tumorigenesis [20]. STK11 has been reported to play a critical role in P53-mediated cell apoptosis [10]. STK $11^{+/-} / P 53^{+/-}$mice showed a dramatically reduced life span and increased tumor incidence compared to the mice with either STK11 or P53 single gene knockout, indicating that P53 and STK11 gene mutations cooperate in tumor progression [21].

In this study, we identified mutations in STK11 gene from Chinese PJS probands, and observed the changes in P53 activity brought by different STK11 mutants and their association with the canceration in PJS.

\section{Methods}

\section{Patient and sample collection}

Materials in this study were collected retrospectively. A total of 154 PJS patients were ascertained in Airforce General Hospital of PLA between May 2013 and April 2016. Blood samples of the probands and all available family members were collected after obtaining informed consent. This study was approved by the Medical Ethics Committee, Airforce General Hospital of PLA. Only PJS patients with both complete information and mutation detected and successfully constructed were included in final analysis.

Clinical diagnosis for PJS was based on the presence of any one of the following clinical findings which was recommended by WHO [22]: (1) three or more histologically confirmed PJ polyps (PJP) in the gastrointestinal tract, (2) any number of PJPs detected with a positive family history of PJS, (3) characteristic mucocutaneous pigmentation with a positive family history of PJS, and (4) any number of PJPs together with characteristic mucocutaneous pigmentation (MP).

\section{Genomic DNA isolation and mutation analysis}

Genomic DNA of peripheral blood leucocytes was extracted routinely by animal genomic DNA kit (TSP201, TsingKe Biotech, Beijing, China) according to the manufacturer's instructions. All 9 coding exons and their flanking sequences of the STK11 gene were amplified by the use of primers listed in Additional file 1: Table. S1. Polymerase chain reactions (PCR) of STK11 exons were performed in a 50-ul reaction which contained $0.4 \mathrm{uM}$ of each primer, $50 \mathrm{ng}$ genomic DNA, and $25 \mathrm{ul} 2 \times$ modified DNA polymerase mix (TSE004, TsingKe Biotech, Beijing, China). The PCRs were performed under the following conditions: denaturation at $95{ }^{\circ} \mathrm{C}$ for $4 \mathrm{~min}$, followed by 35 thermal cycles, each composed of $95{ }^{\circ} \mathrm{C}$ for $30 \mathrm{~s}, 58{ }^{\circ} \mathrm{C}$ for $30 \mathrm{~s}$, and $72{ }^{\circ} \mathrm{C}$ for $45 \mathrm{~s}$.

All available family members underwent STK11 germline mutation test to confirm cosegregation of the mutation with the disease. For frameshift mutation, $\mathrm{T}$ vector assay (pClone007 Vector Kit, TSV-007, TsingKe Biotech, Beijing, China) was used to identify each haplotype by constructing monoclonal cells [23]. In order to rule out polymorphisms and to confirm the pathogenic effects of the variations, 100 chromosomes from 50 unrelated ethnicity-matched healthy individuals were also screened for the presence of the mutations. Allele frequency of each mutation in ExAC was checked [24].

The PCR products were gel- and column-purified and directly sequenced. The purified PCR fragments were then sequenced using BigDye Terminator on an ABI Prism 3100 genetic analyzer (Applied Biosystems, Foster City, CA, USA) by Majorbio Co. Ltd. (Shanghai, China). The results were used to performance sequence alignment according to STK11 gene sequence (NP_000446.1 and NM_000455.4 in GRCh38.p7). All experiment details above had been reported previously [23, 25].

\section{Function prediction and analysis, and association with Clinicopathological features}

To predict the effects of mutations in STK11, PolyPhen-2 (http://genetics.bwh.harvard.edu/pph2) and SIFT (http:// sift.jcvi.org/) were used for specific mutations.

To investigate the impact on P53 activity, we employed dual-luciferase reporter gene technique. Human STK11 cDNA was amplified from the HEK293T cells, and cloned into pcDNA3.1 (+) (V790-20, Carlsbad, CA) vector to create expression vectors of wild type (wt) and mutant (mu) of STK11 gene. The mutant site was generated by site-directed substitution (D0206, Beyotime, Nantong, Jiangsu, China).

The luciferase reporter plasmid pp53-TA-luc which contained a P53-responsive element (D2223, Beyotime, Nantong, Jiangsu, China) was transfected into the cells, together with pRL-TK vector (E2241, Promega, Madison, WI) and pcDNA3.1(+)-STK11 expression vector, using the Lipo6000 transfection reagent (C0526, Beyotime, Nantong, Jiangsu, China). pRL-TK vector expresses wildtype Renilla luciferase reporter and is used as internal control by cotransfected with pp53-TA-luc. Twenty-four hours after transfection, cells were lysed in a passive lysis buffer, which was a component of Dual-Luciferase ${ }^{\ominus}$ Reporter Assay Systems (E1910, Promega, Madison, WI) [26]. According to the manufacturer's protocol, luciferase activity was measured with the Synergy 2 modular multi-mode reader (BioTek Instruments, Winooski, VT). The ratio of pp53 to pRL-TK was calculated in each assay. Each experiment was repeated triple times from cell seeding to luciferase activity measurement. Data 
were showed as mean \pm standard deviation. Student's $t$ test was used to test the significance, and $p<0.05$ was considered as significant.

Factors related to cancer history including sex, family history and P53 activity change were compared using the Fisher exact test, and $p<0.05$ was considered as significant.

\section{Results}

During the period investigated, 154 PJS patients were diagnosed in our department, among whom, 89 declined to participant in mutation test, and 26 had inadequate information. Finally, 39 patients from 31 unrelated families had blood samples collected and received mutation detection. A total of 17 disease-specific mutations in STK11 were detected in 31 probands. Since 3 mutations concerning splicing site (c.290+1G > A, c.734-1G > A, c.863-8_870del16bp) could not be investigated by reporter gene assay, and one mutation (c.426_448del23bp) was hard to be generated by site-directed mutagenesis, there were 13 mutants involved in the final analysis (Additional file 2: Figure S1). Expression vectors of the wild-type and the 13 mutant STK11 gene were constructed for function analysis, and the corresponding PJS families and individuals were included in analysis.

\section{Clinical features}

As shown in Table 1, the 13 probands from unrelated families were 7 familial and 6 sporadic patients, and their native places were various in China (Additional file 1: Table S2). The median age of diagnosis, first polypectomy and at present was 25, 28 and 33 years. Seven of these families (PJS03, 05, 06, 07, 09, 10 and 12) showed autosomal dominant pattern and the remaining 6 cases (PJS01,

Table 1 Characteristics of the cohort with PJS

\begin{tabular}{|c|c|c|c|}
\hline \multicolumn{2}{|l|}{ Characteristics } & \multicolumn{2}{|c|}{ Number (percentage) } \\
\hline \multicolumn{2}{|c|}{ Probands with mutation test } & 31 & \\
\hline \multicolumn{2}{|c|}{ Mutation detected } & 17 & $54.8 \%$ \\
\hline \multicolumn{2}{|c|}{ Probands enrolled in the luciferase analysis } & \multicolumn{2}{|c|}{13} \\
\hline \multirow{3}{*}{$\begin{array}{l}\text { Age }^{a} \\
\text { Median (range) }\end{array}$} & $\mathrm{D}$ & \multicolumn{2}{|c|}{$25(12-37)$ years } \\
\hline & $\mathrm{F}$ & \multicolumn{2}{|c|}{$28(11-39)$ years } \\
\hline & P & \multicolumn{2}{|c|}{$33(24-51)$ years } \\
\hline \multicolumn{4}{|l|}{ Gender } \\
\hline \multicolumn{2}{|l|}{ Male } & 7 & $51.8 \%$ \\
\hline \multicolumn{2}{|l|}{ Female } & 6 & $48.2 \%$ \\
\hline \multicolumn{4}{|l|}{ Family history } \\
\hline \multicolumn{2}{|l|}{ Familial } & 7 & $51.8 \%$ \\
\hline \multicolumn{2}{|l|}{ Sporadic } & 6 & $48.2 \%$ \\
\hline \multicolumn{2}{|l|}{ Cancer history } & 5 & $38.5 \%$ \\
\hline
\end{tabular}

a $D$, diagnosis; $F$, first polypectomy or laparotomy; $P$, present. There were 12 probands having polypectomy
02, 04, 08, 11 and 13) are sporadic (Fig. 1a). MP on the lips, buccal mucosa, and digits were observed at all patients (Fig. 1b). Twelve probands in these families underwent laparotomy or polypectomy due to intussusception or intestinal obstruction (Fig. 1c and d). Three probands of these families (PJS03, 06 and 11) in this study had developed colon cancer before 40 years old (Fig. 1e), and cancer history existed in 3 families (PJS06, 09 and 12). Detail information is showed in Table 2.

\section{Mutation analysis}

Sequencing analysis identified 13 mutations of STK11 gene in the 13 probands which were included in the function analysis (Table 2, Fig. 2a). Most of the mutations have been previously reported [25, 27-29] except for c.924G > A (Fig. 3). The 13 mutations included 8 truncating mutations (4 frameshift and 4 nonsense) and 5 missense mutations. Regarding frameshift mutations, those of PJS05, 06 and 07 (p.P281Rfs*6, p.P281Pfs*4 and p.L285Lfs*2) led to a partial loss of the kinase domain and a completed loss of the C-terminal, and the one in PJS11 (p.P321Hfs*38) led to a partial loss of the $\alpha$-helix of the C-terminus. PJS02, 03, 04 and 10 possessed nonsense mutations of STK11 that resulted in the production of truncated proteins (p.E65*, p.K84*, p.Y118* and p.W308*) (Additional file 2: Figure S2A). Among the PJS cases owning the 13 mutations, 7 were familial and 6 were sporadic, and 5 of them were associated with cancer history. Tested in 100 chromosomes from control individuals, 16 of the detected mutations were not discovered and only c. $1062 \mathrm{C}>\mathrm{G}$ was detected in 5/100 controls. c. $1062 \mathrm{C}>\mathrm{G}$ and c. $1225 \mathrm{C}>\mathrm{T}$ were recorded in ExAC database with allele frequencies of 0.005757 and 0.000147 , and all other mutations were not recorded (Table 2).

\section{Function analysis and association with Clinicopathological features}

Analyzed using PolyPhen-2, missense mutation c.911 was predicted as probably damaging, mutations c.56, c.862 and c.1225 were predicted as possible damaging, while c.1062 was benign (Table 2).

Analyzed using SIFT, missense mutation c.56 and c.1225 were predicted as intolerated, and mutations c.862, c.911 and c.1062 were tolerated (Table 2).

P53 activity was measured using dual-luciferase reporter gene technique after cotransfection of pp53-TA-luc, pRL-TK vector, and pcDNA3.1 (+)-STK11-wt or -mu. Luciferase activity was significantly elevated when STK11-wt was transfected into HEK293T cells. Using the elevation caused by STK11-wt as control, elevations by mutants c.193, c.250, c.354, c.842, c.843 and c.855 were significantly reduced, while those by mutants c.56, c.862, c.911, 

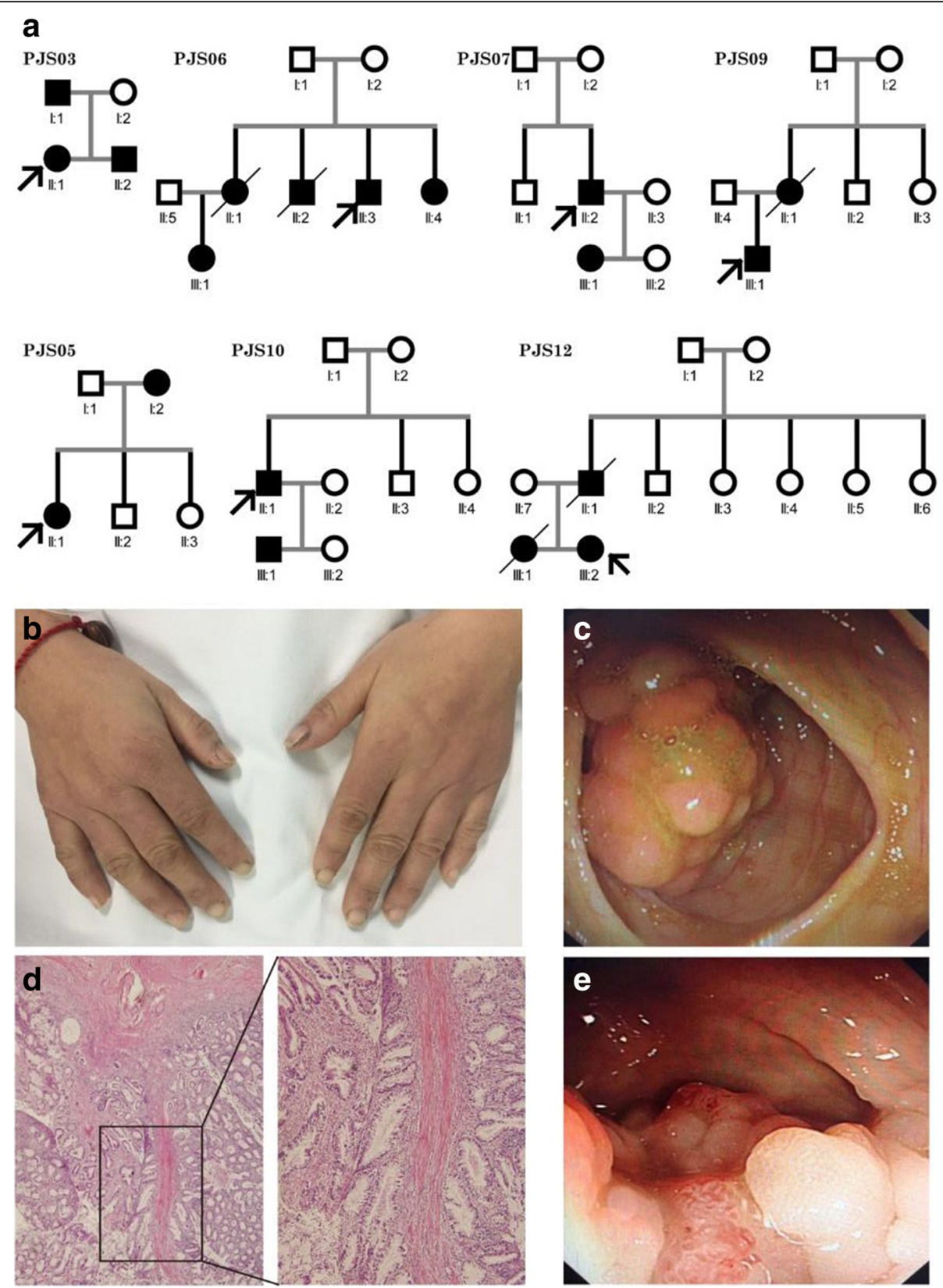

Fig. 1 Genogram and Clinicopathological feature of PJS patients. a Pedigrees of the 7 PJS cases with positive family history. Roman numerals indicate generations and Arabic numbers indicate individuals. Squares = males, circles = females. Affected individuals are denoted by solid symbols and unaffected individuals are denoted by open symbols. The probands are indicated by arrows. $\mathbf{b}$ and $\mathbf{c}$. Melanin pigmentation spots of the fingers, endoscopic view of the recurrent polyp near the anastomotic stoma after the radical surgery of colon cancer and were observed in the proband of PJS03. $\mathbf{d}$ Hematoxylin-eosin-stained tissue slices of the polyp specimens above confirm hamartomatous. Left, $\times 40$ magnification; right, $\times 100$ magnification. e Endoscopic view of the polyps in PJS11, one of which had cancerogenesis

c.924, c.962_963, c.1062 and c.1225 were not changed significantly (Fig. 2b).

There were total 5 families with cancer history (PJS03, 06, 09, 11 and 12). Within the 5 cancer families, P53 activity was reduced and cancer occurred before 40 in 2 families (PJS03 and 06), while in the other 3 families,
P53 activity was not significantly changed and cancers happened after 45 years old (PJS09, 11 and 12) (Table 3).

Through Fisher exact test, none of the factors (sex, family history and P53 activity change) was significantly associated with cancer in PJS (Additional file 1: Table S3). 


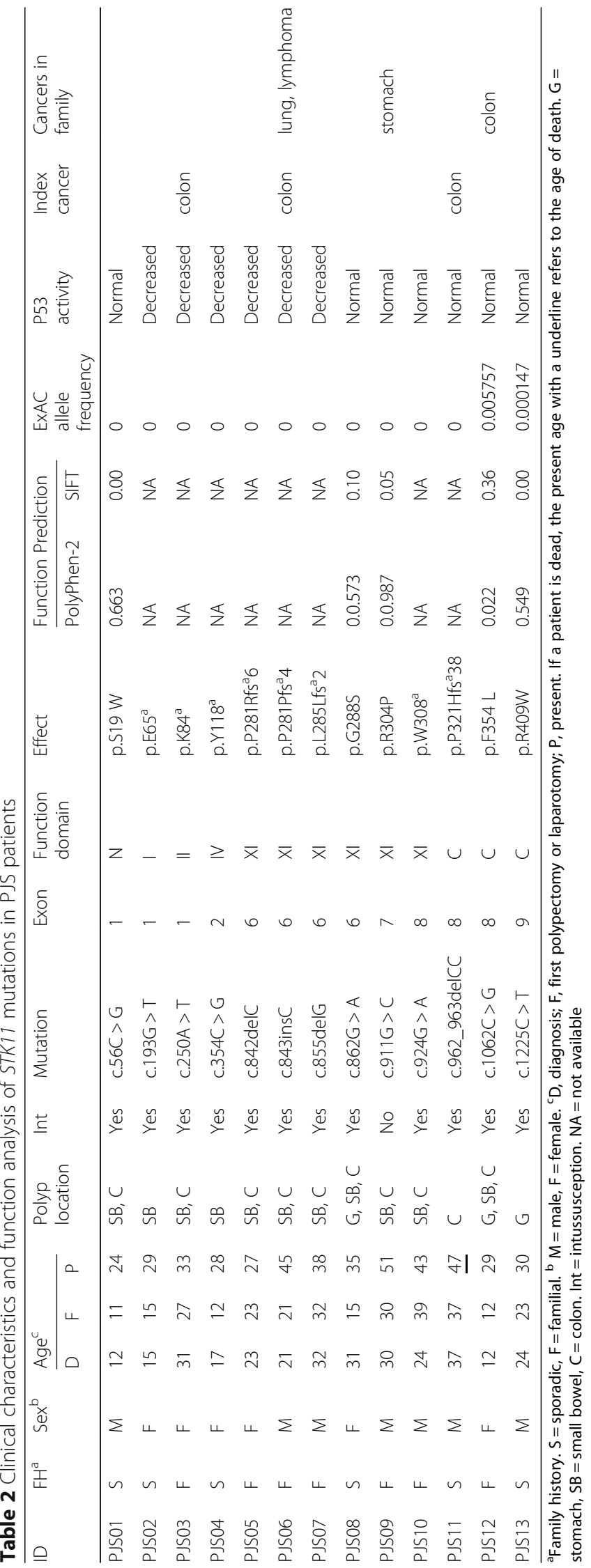



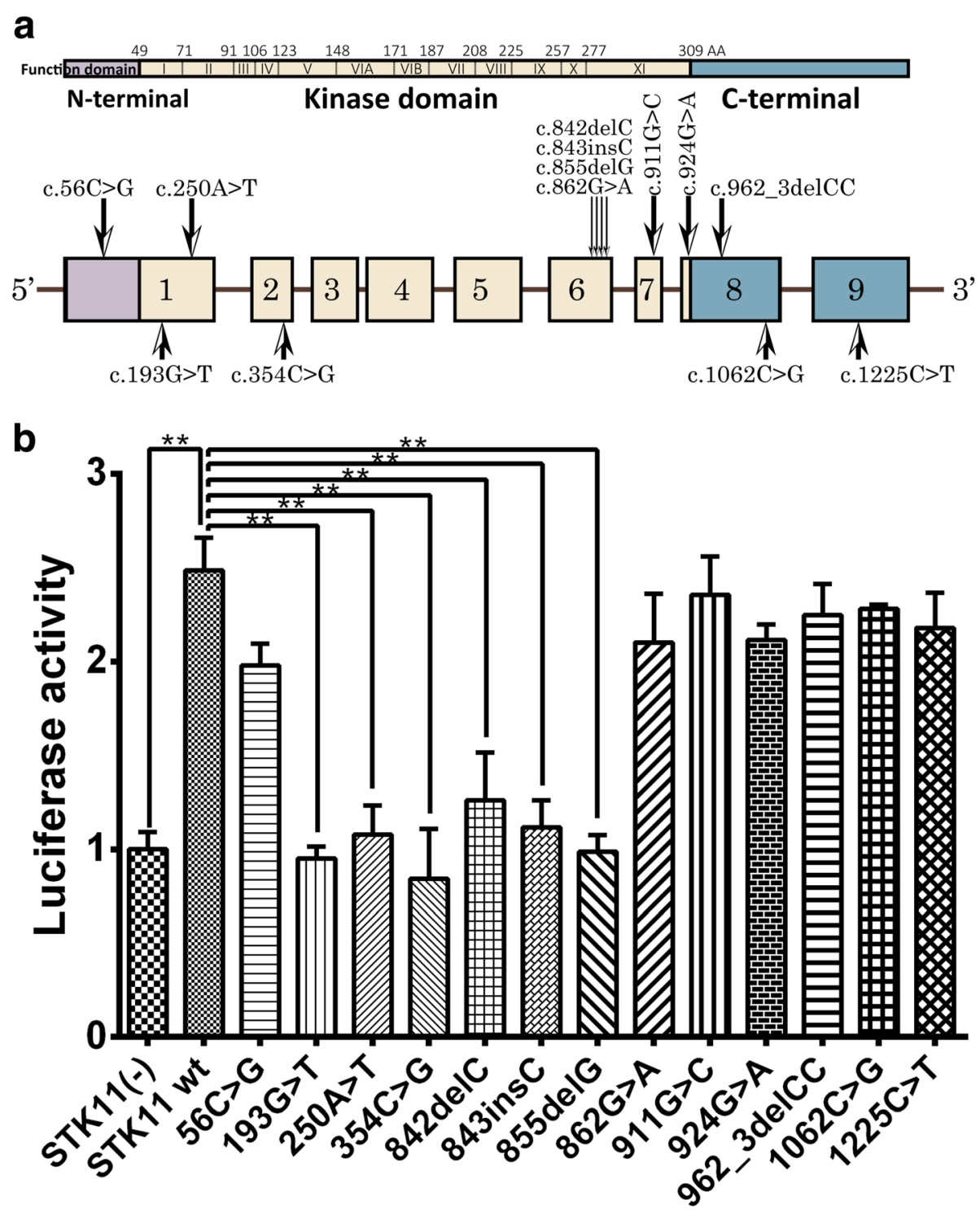

Fig. 2 Distribution of all the STK11 mutations detected (a) and P53 pathway activity tested by dual-luciferase reporter gene technique in HEK293T cells transfected with these mutants (3 replicates) $(\mathbf{b})$. Double-asterisks present significant $(p<0.05)$

\section{Discussion}

Peutz-Jeghers syndrome (PJS) has various manifestations related to GI polyps, such as abdominal pain, rectal blood loss, chronic anemia, prolapsed rectal polyp, bowel obstruction and clinical intussusception [30-32]. Beyond these symptoms, PJS patients also have an increased risk of cancer at multiple sites, including the GI tract, breast, ovary, testis, and lung [33]. As the only validated and the major pathogenic gene in PJS, STK11 is involved in cell cycle regulation and apoptosis, whose abnormality can induce and promote tumorigenesis. It has been proven that STK11-mediated cell cycle regulation has been shown to be regulated via P53-dependent and P53-independent mechanisms [34-39]. STK11 can directly interact with and phosphorylate P53, and to mediate P53-induced apoptosis [40]. What's more, PJS-associated STK11 mutants can diminish P53 activity [41].

In our study, we investigated the effect of STK11 mutations on the transcriptional activity of P53, and we found that six of them inhibited the activity significantly compared with the wild-type. All of the 6 mutations resulted in protein truncation, and all the truncated protein lost partial kinase domain and completed C-terminal. The other seven mutations which didn't significantly decrease P53 activity located in the margin of or outside the kinase domain, and they caused only single amino acid change in the margin of or outside the kinase domain or loss of C-terminal regulatory domain. So we suspected the main part of the kinase domain or 


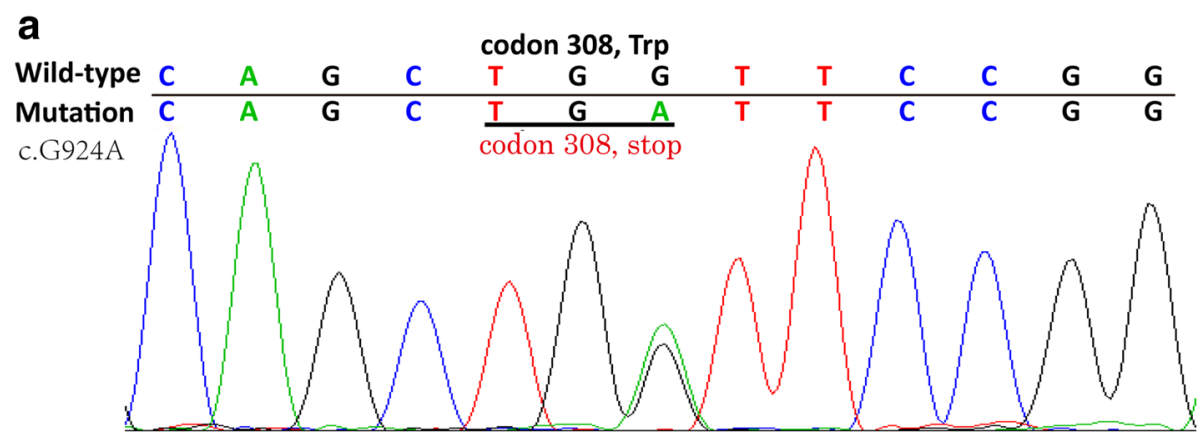

b

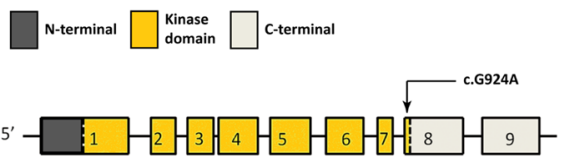

C

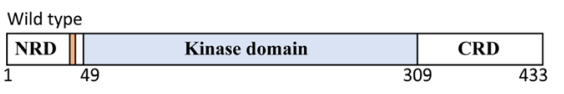

d

Index Patient

Human Ref

Chimpanzee

Macaca mulatta

Rattus norvegicus

Mus musculus

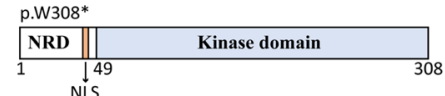

Chicken

Canis lupus familiaris
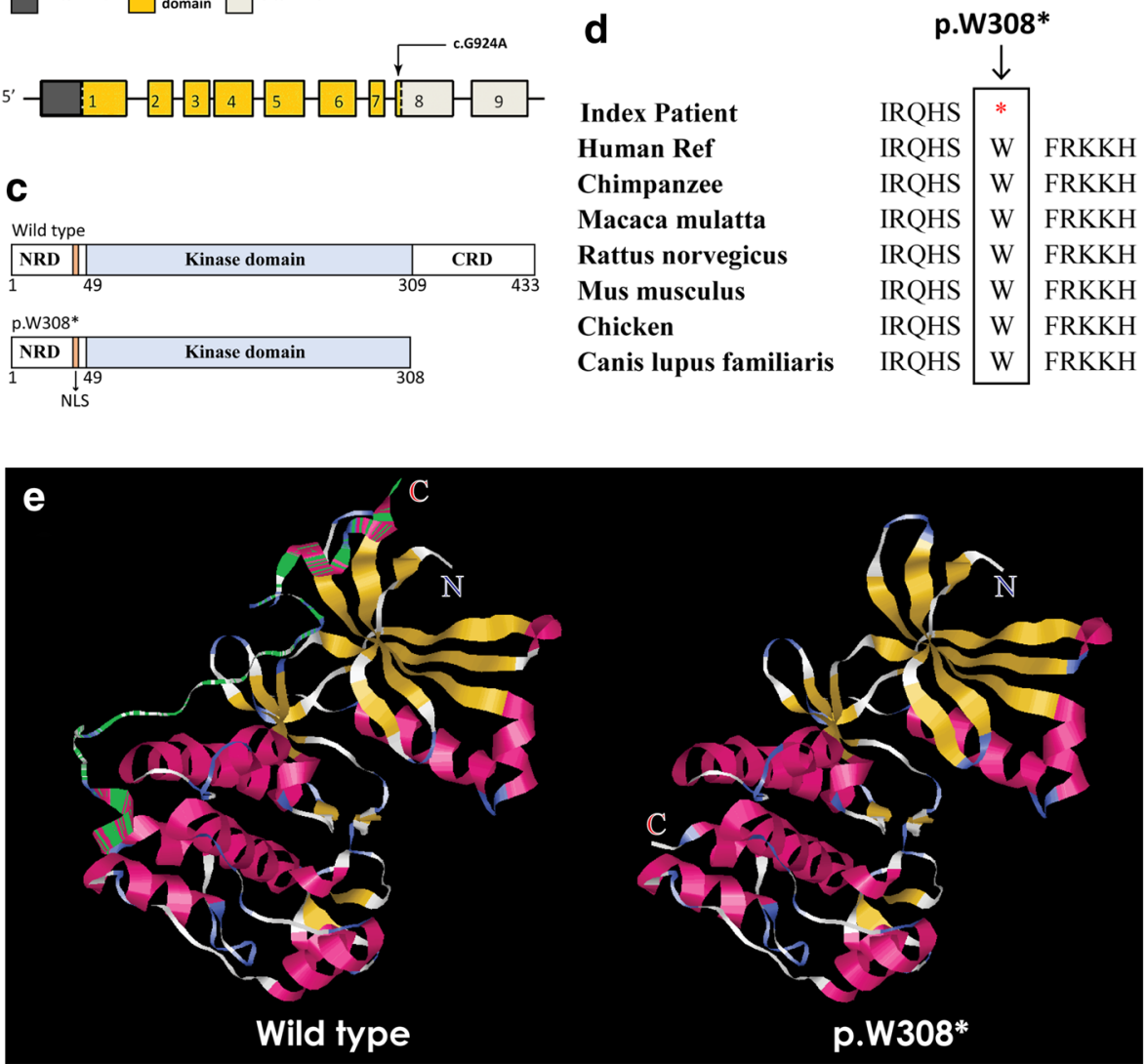

Fig. 3 Details about the novel mutation c.G924A (p.W308*). a Sanger sequencing showed a heterozygous mutation. b The structure of STK11 gene. The mutation is located in exon 8. c Schematics of the secondary structure or functional domains of the STK11 protein. The mutant protein results in a partial loss of kinase domain and a complete loss of the C-terminal domain compared to the wild type. NLS, Nuclear localization signal, NRD or CRD, N- or C-terminal regulatory domain. $\mathbf{d}$ Evolutionary conservation of amino acid residues altered across different species. e The mutant proteins was predicted to result in partial loss of the kinase domain and complete loss of the C-terminal domain of the a-helix (which is labelled using green gaps in the wild type protein) by Swiss-Model online software (http://swissmodel.expasy.org/) compared to the wild type (for which the 3D template model used was 2wtk.2.C) [46]

some key points within it was key for STK11 depended P53 activity rather than the boundary of it or regulatory parts, and truncating mutations were easier to cause the change since they usually resulted in large-scale loss of the amino acid residues. We also encountered three splice site mutations, which cannot be investigated by the luciferase assay. Since splicing errors usually cause exon skipping or abnormal mRNA processing and mRNA degradation, the large-scale changes may also result in P53 activity decrease. But due to the limitation of patient number, the assumption cannot be justified at the present. 
Table $\mathbf{3}$ Characteristics of affected individuals in PJS families with cancer history

\begin{tabular}{|c|c|c|c|c|c|c|c|c|c|c|c|c|}
\hline \multirow[t]{2}{*}{ Family } & \multirow[t]{2}{*}{ Individual } & \multirow[t]{2}{*}{ Sex } & \multicolumn{5}{|c|}{$\mathrm{Age}^{\mathrm{b}}$} & \multirow[t]{2}{*}{ Cause of death } & \multirow[t]{2}{*}{ Mutation } & \multicolumn{2}{|l|}{ Prediction } & \multirow{2}{*}{$\begin{array}{l}\text { P53 } \\
\text { activity }\end{array}$} \\
\hline & & & MP & D & $F$ & C & $P$ & & & PolyPhen & SIFT & \\
\hline \multirow[t]{3}{*}{ PJSO3 } & |:1 & M & NR & NR & NR & 60 & $\underline{60}$ & Colon cancer & \multirow{3}{*}{$\begin{array}{l}\text { c. } 250 \mathrm{~A}>\mathrm{T} / \\
\text { p.K84 }\end{array}$} & \multirow[t]{3}{*}{ NA } & \multirow[t]{3}{*}{ NA } & \multirow[t]{3}{*}{ Decreasec } \\
\hline & $\|: 1^{a}$ & $\mathrm{~F}$ & 5 & 31 & 27 & 27 & 33 & Colon cancer & & & & \\
\hline & $\|: 2$ & M & 6 & 19 & 26 & - & 28 & - & & & & \\
\hline \multirow[t]{5}{*}{ PJSO6 } & $\|: 1$ & F & NR & NR & NR & NR & $\underline{40}$ & Lung cancer & \multirow{5}{*}{$\begin{array}{l}\text { c.843insC/ } \\
\text { p.P281Pfs } 4\end{array}$} & \multirow[t]{5}{*}{ NA } & \multirow[t]{5}{*}{ NA } & \multirow[t]{5}{*}{ Decreasec } \\
\hline & $\|: 2$ & M & NR & NR & NR & NR & 39 & Lymphoma & & & & \\
\hline & $11: 3^{\mathrm{a}}$ & M & 3 & 21 & 21 & 39 & 45 & Colon cancer & & & & \\
\hline & $\|: 4$ & F & 3 & 20 & 20 & - & 39 & - & & & & \\
\hline & $\|1\|: 1$ & $\mathrm{~F}$ & 3 & 11 & 18 & - & 30 & - & & & & \\
\hline \multirow[t]{2}{*}{ PJS09 } & $\|: 1$ & $\mathrm{~F}$ & NR & 55 & NR & 65 & $\underline{65}$ & Stomach cancer & \multirow{2}{*}{$\begin{array}{l}\text { c. } 911 \mathrm{G}>\mathrm{Cl} \\
\text { p.R304P }\end{array}$} & \multirow[t]{2}{*}{ Probable damaging } & \multirow[t]{2}{*}{ Tolerated } & \multirow[t]{2}{*}{ Normal } \\
\hline & $\| l \mid 1^{a}$ & M & 7 & 30 & 30 & - & 51 & - & & & & \\
\hline PJS11 & Index ${ }^{a}$ & M & 6 & 37 & 37 & 47 & $\underline{47}$ & Colon cancer & $\begin{array}{l}\text { c.962_963delCC/ } \\
\text { p.P321 Hfs } 38\end{array}$ & NA & NA & Normal \\
\hline \multirow[t]{3}{*}{ PJS12 } & $\|: 1$ & M & NR & 43 & 43 & 48 & $\underline{52}$ & Colon cancer & \multirow{3}{*}{$\begin{array}{l}\text { c.1062C > G/ } \\
\text { p.F354 L }\end{array}$} & \multirow[t]{3}{*}{ Benign } & \multirow[t]{3}{*}{ Tolerated } & \multirow[t]{3}{*}{ Normal } \\
\hline & $\|1\|: 1$ & $\mathrm{~F}$ & 4 & 15 & - & - & $\underline{16}$ & Bowel obstruction & & & & \\
\hline & $\|1\|: 2^{a}$ & $\mathrm{~F}$ & 4 & 12 & 12 & - & 29 & - & & & & \\
\hline
\end{tabular}

${ }^{a}$ Probands. ${ }^{b} \mathrm{MP}$, melanin pigmentation; $\mathrm{D}$, diagnosis; $\mathrm{F}$, first polypectomy or laparotomy; $\mathrm{C}$, canceration; $\mathrm{P}$, present. If a patient is dead, the present age with a underline refers to the age of death. $M=$ male, $F=$ female. $N A=$ not applicable. $N R=$ not reported

As to the association between P53 activity reduction and cancerogenesis, there is no significance under statistical analysis. One of the reasons is the limited number of cases involved in analysis, just like another two analyses (sex and family history) without statistical significance. When analysed one by one, we can discover some implications from them. Early onset is a distinguishing feature of inherited cancer, and among our cases, there are cancers patients younger than 40 in PJS03 and 06 whose P53 activity is reduced by their mutations. While in PJS09, 11 and 12, cancer patients are older than 45, which means they are more like sporadic ones. Though there is a death case of youth in PJS12, it is not a certain case of cancer. More important, the mutation c. $1062 \mathrm{C}>\mathrm{G}$ is now regarded as a benign variation according to guideline from American College of Medical Genetics and Genomics (ACMG) [42, 43]. So most likely there is a large scale deletion rather than point mutation like c. $1062 \mathrm{C}>\mathrm{G}$ which is to blame. Another possibility is that P53 pathway is not the key one taking part in these three PJS families' cancerogenesis, and some non-P53 pathways leads to the occurrence of tumors.

There are still four families without cancer diagnosed, whose mutations were tested to impact P53 activity. The four mutation carriers are still young (29, 28, 27 and 38 years), so it is important to carry out a more rigorous and comprehensive follow-up as cancer prevention before any advanced methods come up. As to the other four PJS families carrying STK11 mutations without significant P53 activity change, routine surveillance is still necessary to keep them uneventful. The recommendations for PJS management produced by Mallorca conference 2007 is a comprehensive and widely accepted one, which we can refer to $[44,45]$.

There are several important limitations to note. First, here we try to elucidate the pathways of tumorigenesis in PJS by investigating the P53 activity change caused by STK11 mutations, but the mutations are not evenly distributed within the coding sequence and the limited number of cases involved largely limits the results. Second, quite a few of STK11 mutations in PJS are large fragment deletion, so it is necessary to perform test like multiplex ligation-dependent probe amplification (MLPA) assay to make a more comprehensive analysis in the future. Finally, this is a single center study, and the data here may not be the whole picture of PJS in China. It will be very helpful if there is a national database of PJS patients.

\section{Conclusions}

The affected P53 activity caused by STK11 mutations in PJS patients is significantly associated with protein truncation, while cancer risk in PJS can be elevated through pathways rather than P53 pathway. P53 activity test is probably a useful supporting method to predict cancer risk in PJS, which could be helpful in clinical practice. 


\section{Additional files}

Additional file 1: Table S1. Primers for exon-specific sequencing of STK11 gene. Table S2. Native place of PJS patients. Table S3. Association between cancer history and certain factors in the cohort of PJS. (DOCX $24 \mathrm{~kb}$ )

Additional file 2: Figure S1. Flow diagram of patients enrollment. PJS indicates Peutz-Jeghers syndrome. Figue S2. The predicted protein structure of 8 truncating mutations (A) and the PolyPhen-2 prediction results for 5 missense mutations (B). NLS, nuclear location signal. Figure S3. Western blot results of the mutation investigated. Targeted protein: STK11; internal reference: GAPDH. (ZIP 2634 kb)

\section{Abbreviations}

DBE: Double-balloon enteroscopy; Gl: Gastrointestinal; MLPA: Multiplex ligation-dependent probe amplification; MP: Melanin pigmentation; PCR: Polymerase chain reaction; PJP: Peutz-Jeghers syndrome polyp; PJS: Peutz-Jeghers syndrome; STK11: Serine/threonine kinase 11

\section{Acknowledgements}

We thank the subjects for their participation. We appreciate very much for Dr. Wen-Sheng LIN and Dr. Hong-Yu CHEN's kindly help with the pathologic and endoscopic pictures of the polyps.

\section{Funding}

This work was supported by National Natural Science Foundation of China (81500490), Application Research of Capital Clinical Character (Z151100004015215), Annual Project of Airforce General Hospital of PLA (KZ2015026 and KZ2016021), Discipline Construction Project - 1255 of Changhai Hospital (CH125530800) and National Key R\&D Program of China (2017YFC1308802)

\section{Availability of data and materials}

The datasets used and analysed during the current study available from the corresponding author on reasonable request.

\section{Authors' contributions}

$H W, J L$ and XWJ collected the samples and did the follow-up. YLJ and ZYZ performed experiments and did the analysis. EDY, BRL and FY designed the study and supervised the study. ZYZ wrote the manuscript SHS and SBN supervised the study and revised the manuscript. All of the co-authors have read this manuscript and support this submission. All authors read and approved the final manuscript.

\section{Ethics approval and consent to participate}

This study was approved by the Medical Ethics Committee, Airforce General Hospital of PLA and complied with the Declaration of Helsinki. The approval number of this study is AFGHEC2016145. All of the adult participants and the legal guardians of children participants were informed to participate in this study with written consents.

\section{Consent for publication}

Written informed consents for publication of their clinical details and images were obtained from adult participants and the legal guardians of children participants in this study.

\section{Competing interests}

The authors declare that they have no competing interests.

\section{Publisher's Note}

Springer Nature remains neutral with regard to jurisdictional claims in published maps and institutional affiliations.

\section{Author details}

${ }^{1}$ Hebei North University, Zhangjiakou 075061, Hebei Province, China. 2Department of Gastroenterology, Airforce General Hospital of PLA, Beijing 100142, China. ${ }^{3}$ Department of Medical Genetics, Naval Medical University, Shanghai 200433, China. ${ }^{4}$ Department of Colorectal Surgery, Changhai Hospital, Shanghai 200433, China.
Received: 27 December 2017 Accepted: 13 June 2018

Published online: 09 August 2018

\section{References}

1. Giardiello FM, Brensinger JD, Tersmette AC, Goodman SN, Petersen GM, Booker SV, Cruz-Correa M, Offerhaus JA. Very high risk of cancer in familial Peutz-Jeghers syndrome. Gastroenterology. 2000;119(6):1447-53.

2. Boardman LA, Thibodeau SN, Schaid DJ, Lindor NM, McDonnell SK, Burgart $\sqcup$, Ahlquist DA, Podratz KC, Pittelkow M, Hartmann LC. Increased risk for cancer in patients with the Peutz-Jeghers syndrome. Ann Intern Med. 1998; 128(11):896-9.

3. Giardiello FM, Trimbath JD. Peutz-Jeghers syndrome and management recommendations. Clin Gastroenterol Hepatol. 2006:4(4):408-15.

4. Resta N, Pierannunzio D, Lenato GM, Stella A, Capocaccia R, Bagnulo R, Lastella P, Susca FC, Bozzao C, Loconte DC, et al. Cancer risk associated with STK11/LKB1 germline mutations in Peutz-Jeghers syndrome patients: results of an Italian multicenter study. Dig Liver Dis. 2013;45(7):606-11.

5. Jenne DE, Reimann H, Nezu J, Friedel W, Loff S, Jeschke R, Muller O, Back W, Zimmer M. Peutz-Jeghers syndrome is caused by mutations in a novel serine threonine kinase. Nat Genet. 1998:18(1):38-43.

6. Hemminki A, Markie D, Tomlinson I, Avizienyte E, Roth S, Loukola A, Bignell G, Warren W, Aminoff M, Hoglund P, et al. A serine/threonine kinase gene defective in Peutz-Jeghers syndrome. Nature. 1998;391(6663):184-7.

7. Hanks SK, Quinn AM, Hunter T. The protein kinase family: conserved features and deduced phylogeny of the catalytic domains. Science. 1988; 241(4861):42-52.

8. Boudeau J, Baas AF, Deak M, Morrice NA, Kieloch A, Schutkowski M, Prescott AR, Clevers HC, Alessi DR. MO25alpha/beta interact with STRADalpha/beta enhancing their ability to bind, activate and localize LKB1 in the cytoplasm. EMBO J. 2003;22(19):5102-14

9. Tiainen M, Ylikorkala A, Makela TP. Growth suppression by Lkb1 is mediated by a G(1) cell cycle arrest. Proc Natl Acad Sci U S A. 1999;96(16):9248-51.

10. Karuman P, Gozani O, Odze RD, Zhou XC, Zhu H, Shaw R, Brien TP, Bozzuto $C D$, Ooi $D$, Cantley LC, et al. The Peutz-Jegher gene product LKB1 is a mediator of p53-dependent cell death. Mol Cell. 2001;7(6):1307-19.

11. Spicer J, Rayter S, Young N, Elliott R, Ashworth A, Smith D. Regulation of the Wnt signalling component PAR1A by the Peutz-Jeghers syndrome kinase LKB1. Oncogene. 2003;22(30):4752-6.

12. Ossipova O, Bardeesy N, DePinho RA, Green JB. LKB1 (XEEK1) regulates Wnt signalling in vertebrate development. Nat Cell Biol. 2003;5(10):889-94

13. Smith DP, Rayter SI, Niederlander C, Spicer J, Jones CM, Ashworth A. LIP1, a cytoplasmic protein functionally linked to the Peutz-Jeghers syndrome kinase LKB1. Hum Mol Genet. 2001;10(25):2869-77.

14. Bardeesy N, Sinha M, Hezel AF, Signoretti S, Hathaway NA, Sharpless NE, Loda M, Carrasco DR, DePinho RA. Loss of the Lkb1 tumour suppressor provokes intestinal polyposis but resistance to transformation. Nat. 2002; 419(6903):162-7

15. Watts JL, Morton DG, Bestman J, Kemphues KJ. The C. elegans par-4 gene encodes a putative serine-threonine kinase required for establishing embryonic asymmetry. Dev (Cambridge, England). 2000;127(7):1467-75.

16. Boudeau J, Sapkota G, Alessi DR. LKB1, a protein kinase regulating cell proliferation and polarity. FEBS Lett. 2003;546(1):159-65.

17. Martin SG, St Johnston D. A role for Drosophila LKB1 in anterior-posterior axis formation and epithelial polarity. Nature. 2003;421(6921):379-84.

18. Baas AF, Kuipers J, van der Wel NN, Batlle E, Koerten HK, Peters PJ, Clevers $\mathrm{HC}$. Complete polarization of single intestinal epithelial cells upon activation of LKB1 by STRAD. Cell. 2004:116(3):457-66

19. Vogelstein B, Lane D, Levine AJ. Surfing the p53 network. Nat. 2000 408(6810):307-10.

20. Donehower LA, Harvey M, Slagle BL, McArthur MJ, Montgomery CA Jr, Butel JS, Bradley A. Mice deficient for p53 are developmentally normal but susceptible to spontaneous tumours. Nat. 1992;356(6366):215-21.

21. Wei C, Amos Cl, Stephens LC, Campos I, Deng JM, Behringer RR, Rashid A, Frazier ML. Mutation of Lkb1 and p53 genes exert a cooperative effect on tumorigenesis. Cancer Res. 2005;65(24):11297-303.

22. Aaltonen LA, Hamilton SR. Pathology and genetics of Tumours of the digestive system. Lyon: IARC Press; 2010.

23. Zhao ZY, Jiang YL, Li BR, Yang F, Li J, Jin XW, Ning SB, Sun SH. A 23nucleotide deletion in STK11 gene causes Peutz-Jeghers syndrome and malignancy in a Chinese patient without a positive family history. Dig Dis Sci. 2017;62(11):3014-20 
24. Lek M, Karczewski KJ, Minikel EV, Samocha KE, Banks E, Fennell T, O'DonnellLuria AH, Ware JS, Hill AJ, Cummings BB, et al. Analysis of protein-coding genetic variation in 60,706 humans. Nat. 2016;536(7616):285-91.

25. Zhao ZY, Jiang YL, Li BR, Yang F, Li J, Jin XW, Ning SB, Sun SH. Sanger sequencing in exonic regions of STK11 gene uncovers a novel de-novo germline mutation (c.962_963delCC) associated with Peutz-Jeghers syndrome and elevated cancer risk: case report of a Chinese patient. BMC Med Genet. 2017:18(1):130.

26. Yu J, Xu QG, Wang ZG, Yang Y, Zhang L, Ma JZ, Sun SH, Yang F, Zhou WP. Circular RNA cSMARCA5 inhibits growth and metastasis in hepatocellular carcinoma. J Hepatol. 2018;68(6):1214-27.

27. Mao X, Zhang Y, Wang H, Mao G, Ning S. Mutations of the STK11 and FHIT genes among patients with Peutz-Jeghers syndrome. Zhonghua Yi Xue Yi Chuan Xue Za Zhi. 2016;33(2):186-90.

28. Mao X, Zhang Y, Mao G, Wang H, Ning S. STK11 gene mutations in patients with Peutz-Jeghers syndrom. World Chin J Digestol. 2015;23(2):332.

29. Zhao ZY, Jiang YL, Li BR, Yu ED, Ning SB. A novel mutation (c.855delG) in STK11 gene is associated with Peutz-Jeghers syndrome in a Chinese family. Dig Liver Dis. 2018;50(3):312-4.

30. Rufener SL, Koujok K, McKenna BJ, Walsh M. Small bowel intussusception secondary to Peutz-Jeghers polyp. Radiographics. 2008;28(1):284-8.

31. Harned RK, Buck JL, Sobin LH. The hamartomatous polyposis syndromes: clinical and radiologic features. AJR Am J Roentgenol. 1995;164(3):565-71.

32. Latchford A, Greenhalf W, Vitone LJ, Neoptolemos JP, Lancaster GA, Phillips RK. Peutz-Jeghers syndrome and screening for pancreatic cancer. Br I Surg. 2006;93(12):1446-55.

33. van Lier MG, Wagner A, Mathus-Vliegen EM, Kuipers EJ, Steyerberg EW, van Leerdam ME. High cancer risk in Peutz-Jeghers syndrome: a systematic review and surveillance recommendations. Am J Gastroenterol. 2010;105(6): 1258-64. author reply 1265

34. Zeng PY, Berger SL. LKB1 is recruited to the p21/WAF1 promoter by p53 to mediate transcriptional activation. Cancer Res. 2006;66(22):10701-8.

35. Tiainen M, Vaahtomeri K, Ylikorkala A, Makela TP. Growth arrest by the LKB1 tumor suppressor: induction of p21(WAF1/CIP1). Hum Mol Genet. 2002; 11(13):1497-504

36. Gurumurthy S, Hezel AF, Sahin E, Berger JH, Bosenberg MW, Bardeesy N. LKB1 deficiency sensitizes mice to carcinogen-induced tumorigenesis. Cancer Res. 2008;68(1):55-63.

37. Scott KD, Nath-Sain S, Agnew MD, Marignani PA. LKB1 catalytically deficient mutants enhance cyclin D1 expression. Cancer Res. 2007;67(12):5622-7.

38. Setogawa T, Shinozaki-Yabana S, Masuda T, Matsuura K, Akiyama T. The tumor suppressor LKB1 induces p21 expression in collaboration with LMO4, GATA-6, and Ldb1. Biochem Biophys Res Commun. 2006;343(4):1186-90.

39. Liang J, Shao SH, Xu ZX, Hennessy B, Ding Z, Larrea M, Kondo S, Dumont DJ, Gutterman JU, Walker CL, et al. The energy sensing LKB1-AMPK pathway regulates p27(kip1) phosphorylation mediating the decision to enter autophagy or apoptosis. Nat Cell Biol. 2007;9(2):218-24.

40. Cheng H, Liu P, Wang ZC, Zou L, Santiago S, Garbitt V, Gjoerup OV, Iglehart $J \mathrm{D}$, Miron A, Richardson AL, et al. SIK1 couples LKB1 to p53-dependent anoikis and suppresses metastasis. Sci Signal. 2009;2(80):ra35.

41. Dai L, Fu L, Liu D, Zhang K, Wu Y, Meng H, Zhang B, Guan X, Guo H, Bai Y. Novel and recurrent mutations of STK11 gene in six Chinese cases with Peutz-Jeghers syndrome. Dig Dis Sci. 2014;59(8):1856-61.

42. Hampel H, Bennett RL, Buchanan A, Pearlman R, Wiesner GL. A practice guideline from the American College of Medical Genetics and Genomics and the National Society of genetic counselors: referral indications for cancer predisposition assessment. Genet Med. 2015;17(1):70-87.

43. Tan $H$, Wei $X$, Yang P, Huang Y, Li H, Liang D, Wu L. A lesson from a reported pathogenic variant in Peutz-Jeghers syndrome: a case report. Familial Cancer. 2017;16(3):417-22.

44. Beggs AD, Latchford AR, Vasen HF, Moslein G, Alonso A, Aretz S, Bertario L, Blanco I, Bulow S, Burn J, et al. Peutz-Jeghers syndrome: a systematic review and recommendations for management. Gut. 2010;59(7):975-86.

45. Syngal S, Brand RE, Church JM, Giardiello FM, Hampel HL, Burt RW, American College of G. ACG clinical guideline: genetic testing and management of hereditary gastrointestinal cancer syndromes. Am J Gastroenterol. 2015;110(2):223-62. quiz 263

46. Biasini M, Bienert S, Waterhouse A, Arnold K, Studer G, Schmidt T, Kiefer F, Gallo Cassarino T, Bertoni M, Bordoli L, et al. SWISS-MODEL: modelling protein tertiary and quaternary structure using evolutionary information. Nucleic Acids Res. 2014;42(Web Server issue):W252-8.

\section{Ready to submit your research? Choose BMC and benefit from:}

- fast, convenient online submission

- thorough peer review by experienced researchers in your field

- rapid publication on acceptance

- support for research data, including large and complex data types

- gold Open Access which fosters wider collaboration and increased citations

- maximum visibility for your research: over $100 \mathrm{M}$ website views per year

At BMC, research is always in progress.

Learn more biomedcentral.com/submissions 